\title{
A case report of hemolytic streptococcal gangrene in the danger triangle of the face with thrombocytopenia and hepatitis
}

\author{
Xiao-ling Jia ${ }^{1}$, Janak L. Pathak², Jin-fa Tong ${ }^{1}$ and Ji-mei Su${ }^{3 *}$
}

\begin{abstract}
Background: Hemolytic streptococcus gangrene is a life threatening invasive bacterial infection. Hemolytic streptococcus gangrene in the danger triangle of the face is too lethal to operate. A case of the confirmed hemolytic streptococcus gangrene in the danger triangle of the face caused by Group A beta-hemolytic streptococcus (GAS) in 20-months old boy is presented to draw attention of clinicians to this uncommon but frequently fatal infection.

Case presentation: Previously healthy 20 months old boy suddenly developed paranasal gangrene on the left side of the danger triangle of the face, followed by rapidly progressive thrombocytopenia and hepatitis. The clinical features, liver function, and hematological and serological parameters resembled to a description of streptococcal toxic shock syndrome (STSS). Aggressive antibiotics, substitutional and supportive therapy were conducted without surgical debridement of facial tissues. Prompt diagnosis and aggressive timely treatment completely cured the disease in 28 days.

Conclusions: The present case report demonstrates prompt diagnosis and timely treatment as a strategy to cure the fatal hemolytic streptococcus gangrene located in too risky body part to operate.
\end{abstract}

Keywords: Hemolytic streptococcus gangrene, Group-a beta-hemolytic streptococcus, The danger triangle of the face, Thrombocytopenia, Hepatitis

\section{Background}

Hemolytic streptococcus gangrene is invasive bacterial infection mainly caused by GAS. Human are the natural hosts and sole reservoirs for GAS. Necrotizing soft tissue infections (NSTI) are among the serious consequences caused by GAS infection. GAS-caused NSTI are characterized by frequent development of shock and high mortality [1]. GAS infection-related in-hospital case fatality rate is reported to be about $11 \%$ [1]. The incidence of the GAS infection has been reported to increase during the last 10-20 years due to the increasing colonization of the GAS in general population [2]. Hemolytic streptococcus gangrene is a fatal disease that causes systemic illness and multisystem failures, such as bacteremia, renal

\footnotetext{
* Correspondence: 6198003@zju.edu.cn

Dr. Janak L. Pathak and Dr. Xiao-ling Jia shared first authorship

Dr. Janak L. Pathak and Dr. Xiao-ling Jia contributed equally to this manuscript.

${ }^{3}$ Department of Stomatology, Children's Hospital, Zhejiang University School of Medicine, NO.3333 Binsheng Road, Hangzhou 310052, Zhejiang Province, People's Republic of China

Full list of author information is available at the end of the article
}

impairment, hepatitis, acute thrombocytopenia and respiratory failure. Hemolytic streptococcus gangrene in the danger triangle of the face is exceedingly lethal and rare. Early diagnosis, aggressive timely treatment and prompt initiation of supportive care are crucial for a good prognosis. We reported a case of early diagnosis and successful treatment of hemolytic streptococcus gangrene in a 20-month-old boy, who developed severe hemolytic streptococcus gangrene in the danger triangle of the face followed by rapidly progressive thrombocytopenia and hepatitis. We diagnosed hemolytic streptococcus gangrene based on the clinical symptoms, signs of the disease, bacterial isolation and identification, hematological markers, serological markers for vital organ test, and B-ultrasonography of liver and spleen.

\section{Case presentations}

A 20-month-old boy was referred to our hospital due to paranasal gangrene on the left side of the maxillofacial danger triangle (Fig. 1). The boy presented with a flu-like syndrome with fever, cough, shivering and sore throat four 


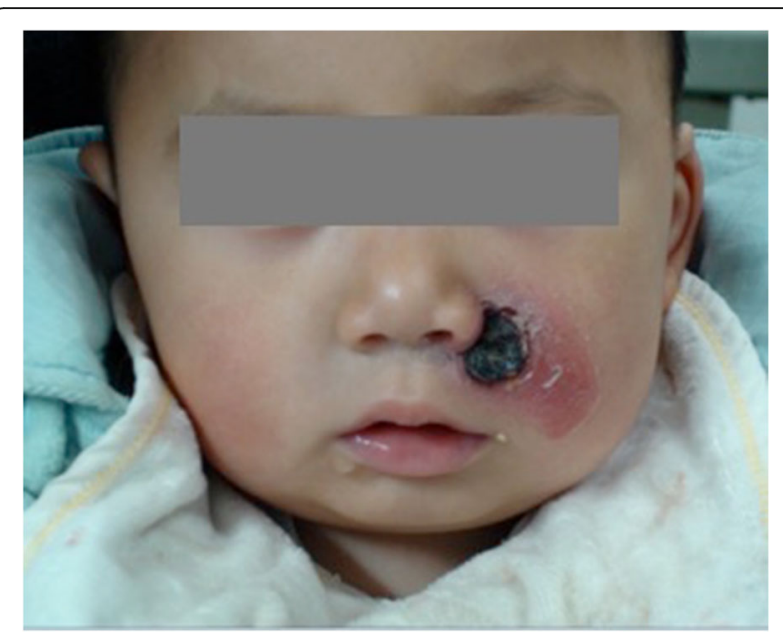

Fig. 1 Image of hemolytic streptococcus gangrene in the left maxillofacial region upon admission

days prior to referral. Redness, swelling and pain occurred along with several vesicles, and a bloody secretion appeared in his left paranasal region two days prior to referral. The boy was given intensive intravenous penicillin $\mathrm{G}$ therapy for four days at the local hospital but there was no sign of regression. Swelling in left paranasal region worsened two days prior to referral. The medical history showed that the boy was born after an uneventful pregnancy, and had a normal growth and development. He had no history of medical illness, including diabetes mellitus or cardiac conditions. No history suggested that trauma, skin abrasions, insect bites or sinusitis had occurred.

Upon admission to our hospital, the patient was conscious and stable but very weak with body temperature of $103.5{ }^{\circ} \mathrm{F}$, a respiratory rate of $32 / \mathrm{min}$, a heart rate of $146 / \mathrm{min}$, and blood pressure of 108/69 $\mathrm{mmHg}$. Steady breathing with slightly red throat was observed. Rough breathing sounds were heard in the both lungs with no rales. The cardiac auscultation revealed a regular rate and rhythm. There was no sign of abdominal tenderness and neurological abnormalities.

A facial examination showed a red, swollen substantially infected area (approximately $4 \times 3 \mathrm{~cm}$ ) that involved the left nasolabial groove, left cheek and left upper lip (Fig. 1). A gangrenous region (approximately $1.5 \times 1.5 \mathrm{~cm}$ ) was found in the left paranasal maxillofacial danger triangle with no purulent secretion (Fig. 1). The gangrene extended into the subcutaneous fat tissue but did not involve the fascia and muscles. The demarcation from areas of necrosis to more normal tissue was nearly clear. The intraoral mucosa was not red or swollen (Fig. 1).

A rapid laboratory examination showed a significantly decreased platelet count of $48 \times 10^{9} / \mathrm{L}$, a reduced hemoglobin (HB) concentration associated with an elevated erythrocyte sedimentation rate (ESR) of $56 \mathrm{~mm} / \mathrm{h}$, and a C-reactive protein (CRP) level of $160 \mathrm{mg} / \mathrm{L}$. Local changes worsened after four days of intravenous penicillin G (800 thousand unit, twice a day) therapy, and the epithelial defect was more prominent with worsening hematoma. Clinical features and laboratory data indicated this case as a more serious illness than initially thought. Empiric antibiotic therapy with intravenous vancomycin $(0.15 \mathrm{~g}$ every $8 \mathrm{~h}$ for 15 days) and meropenem ( $0.15 \mathrm{~g}$ every $8 \mathrm{~h}$ for 9 days) was started immediately to control the facial tissue infection. Surgical debridement of facial tissue was not performed due to risky location of the infection i.e. the danger triangle of the face. Surgery in the danger triangle of the face poses a high risk of intracranial infection, which is often fatal. After $24 \mathrm{~h}$ of patient admission, pus culture report showed heavy growth of GAS along with a small growth of Staphylococcus aureus. Antibacterial sensitivity test showed that both GAS and Staphylococcus aureus were sensitive to vancomycin and meropenem but resistant to penicillin G. After 3 days of treatment, body temperature returned to normal, and the facial infection was controlled. However, the platelet count continued to decrease. Support measures were applied immediately, including intravenous gamma globulin (10 g per day) and hexadecadrol (1 $\mathrm{mg}$ per day) until the platelet count recovered to a normal level. On the 8th day, liver function markers were significantly elevated. Elevated serum glutamic-pyruvic transaminase (GPT, $1645 \mathrm{U} / \mathrm{L}$ ), glutamic oxaloacetic transaminase (GOT, $866 \mathrm{U} / \mathrm{L}$ ) and gamma-glutamyl transpeptidase (GGT, $182 \mathrm{U} / \mathrm{L}$ ) were observed (Table 1). B-ultrasonography revealed hepatosplenomegaly. The patient was treated with hepatinica combined with nutritional supportive therapy. The gangrene in the maxillofacial region began to subside after 7 days (Fig. 2). On the 15th day, the hepatic function was substantially improved.

This patient was therefore diagnosed with hemolytic streptococcal gangrene, thrombocytopenia and hepatitis. Early diagnosis and aggressive timely treatment cured the infection within 28 days.

\section{Discussion and conclusions}

GAS causes about 500,000 deaths every year in the world [3]. GAS possesses considerable extracellular virulence factors to cause infection. These virulence factors are associated with bacterial adhesion and spreading, tissue destruction, immune system evasion, and cellular toxicity [4]. In around $10 \%$ of GAS cases, superantigen toxins produced by the bacteria stimulate a large proportion of $\mathrm{T}$ cells leading to STSS [5]. The pathogen spreads through droplets from parts of an infected tissue [6]. In this case report, patient developed a flu-like syndrome prior to the maxillofacial infection.

The pathogenicity of GAS ranges from mild infections such as impetigo or pharyngitis to severe invasive infections 
Table 1 Laboratory parameters of a patient with hemolytic streptococcus gangrene

\begin{tabular}{|c|c|c|c|c|c|c|c|c|}
\hline Reference value & day 1 & day 2 & day 5 & day 8 & day 11 & day 15 & day 21 & day 28 \\
\hline PLT:100-400*10 $/ \mathrm{L}$ & 48 & 37 & 12 & 106 & 173 & 177 & 212 & 268 \\
\hline HB:110-155 g/L & 79 & 75 & 85 & 86 & 87 & 91 & 105 & 119 \\
\hline ESR:0-20 mm/h & & 56 & 122 & 124 & 111 & 119 & 78 & 64 \\
\hline CRP: $<1 \mathrm{mg} / \mathrm{L}$ & $>160$ & & 44 & 14 & $<1$ & $<1$ & & $<1$ \\
\hline GPT:5-50 U/L & 64 & & & 1645 & 642 & 183 & 90 & 109 \\
\hline GOT:5-55 U/L & 35 & & & 866 & 142 & 48 & 93 & 79 \\
\hline GGT:5-50 U/L & 15 & & & 182 & 107 & 57 & 38 & 29 \\
\hline
\end{tabular}

PLT-Platelet count; ESR-Erythrocyte sedimentation rate; CRP-C-reactive protein GPT-Glutamic-pyruvic transaminase; GOT-Glutamic oxaloacetic transaminase GGT-Gamma-glutamyl transpeptidase

such as hemolytic streptococcus gangrene, necrotizing fasciitis or STSS. Clinical characteristics of GAS are often markedly different in individuals infected with the same strain. Such difference is resulted from a complex interaction between the bacterial virulence factors, the mode of infection and the individual host immunity [7]. GAS genotype emm1 (range 20-33\%) is the leading cause of invasive disease worldwide followed by emm 28 (with a range of $15 \%$ ). Both genotypes are susceptible to penicillin [8]. However, emm3 genotype had also been reported to be more commonly associated with death than other emm genotypes [9]. Therefore, the genotype related severity of GAS is still a controversy.

Old age, cardiopulmonary or hepatorenal diseases, diabetes mellitus, debility, obesity, peripheral arteriovenous malformation or lymphatic insufficiency, and trauma are among the factors associated with the risk of death during invasive streptococcal infection [10-12]. Necrotizing fasciitis carries the highest risk of GAS-related mortality. However necrotizing fasciitis is a relatively rare condition that

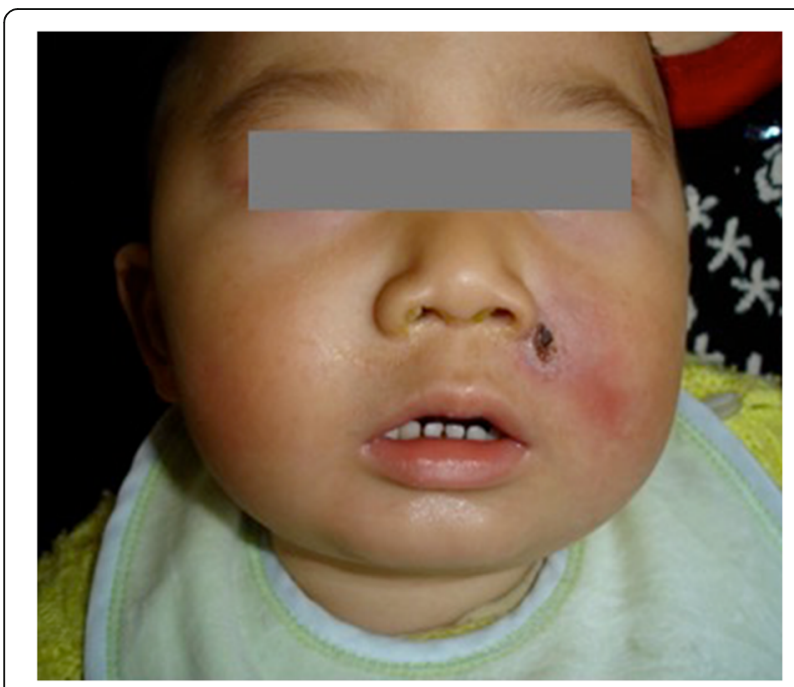

Fig. 2 Image of hemolytic streptococcus gangrene in the left maxillofacial region after 7 days of admission accounts for approximately $10 \%$ of GAS-related deaths [13]. The second most important prognostic factor is the presence of STSS. The mortality rate in patients without STSS and with STSS had been reported to be approximately $30 \%$ and $80-100 \%$ respectively [14]. The time of diagnosis is a very crucial prognostic factor. Distinguishing between simple cellulitis and hemolytic streptococcus gangrene during early course of the infection is a difficult task. A complete blood count, CRP level, and liver and kidney function tests should be ordered for patients with severe infections and comorbidities causing organ dysfunction on admission. Blood cultures are useful in patients with signs of severe and systemic infections [15]. Tissue biopsies are the preferred diagnostic test for necrotizing skin and soft tissue infections [16]. Imaging techniques provide extra evidences for diagnosis of GAS. Clinical examination combined with imaging studies increases the accuracy of diagnosis and the depth of the infection [17]. In this study, early speculation and diagnosis of GAS was a life saving event.

Meleney reported 20 cases of streptococcal gangrene in 1924. He listed extensive gangrene as an essential component of the clinical syndrome [18]. Initial symptoms and signs of hemolytic streptococcus gangrene are often similar to acute thrombophlebitis, acute arthritis, acute vascular occlusion or deep soft-tissue trauma. Approximately 130 cases of GAS with 11 cases involving head and neck have been reported in the literature so far [19]. In our case, hemolytic streptococcus gangrene in facial area was followed by rapidly progressive thrombocytopenia and toxic hepatitis. These clinical features and multisystem effects were similar to a description of STSS [20]. In STSS, only bacterial culture reports distinguish between streptococcal and staphylococcal infection. Therefore, antibacterial choice must include coverage of both streptococcus and staphylococcus. In addition, early administration of intravenous immunoglobulin therapy should be considered in cases of STSS and hemolytic streptococcus gangrene [5]. In our case, both GAS and staphylococcal aureus were sensitive to both empiric antibiotics vancomycin and 
meropenem. We also administrated intravenous gamma globulin and methylprednisolone until the multiple organ function and coagulation disorders were improved.

The basic principle of management of acute hemolytic streptococcus gangrene has not changed from the approaches advocated by Meleney. Meleney recommended prompt diagnosis, empiric polymicrobial antibiotic therapy, inpatient treatment, surgical removal of debridement and nutritional supportive measures to treat GAS [21]. Since GAS is usually sensitive to penicillin, erythromycin, cephalexin, cloxacillin, vancomycin, minocycline or ciprofloxacin [22], penicillin is still the first choice of treatment. However, cases with failure of penicillin to eradicate GAS from GAS carriers are increasing [23]. Moreover, the presence of staphylococci and gram-negative anaerobes during GAS infection suggests for the broad spectrum antibacterial therapy instead of penicillin [24]. In our case, four days of intravenous penicillin $G$ in the local hospital produced no signs of regression. Then established and wide-spectrum antibiotics, such as vancomycin and meropenem, were given intravenously every $8 \mathrm{~h}$. Meropenem could cross the blood-brain barrier to prevent intracranial infection of gangrene in the paranasal maxillofacial danger triangle. We did not perform debridement of necrotic tissue, which would cause severe maxillofacial deformities. We hypothesized that the reasons that the gangrene subsided in this case report were as follows: (a) loose maxillofacial soft tissues with a rich blood supply ensured a strong anti-infection ability, (b) the age of the patient with a strong body metabolism helped to heal the wound, (c) established, sensitive and wide-spectrum antibiotics controlled the infection, (d) prompt diagnosis and aggressive management alleviated the clinical complications and (e) the gangrene did not extend into the fascia and muscles.

This is the first case report of hemolytic streptococcus gangrene in the danger triangle of the face of pediatric patient. The present case report demonstrates that prompt diagnosis and timely treatment could treat the fatal hemolytic streptococcus gangrene and save patients' life.

\section{Abbreviations \\ CRP: C-reactive protein; ESR: Erythrocytes sedimentation rate; GAS: Group A beta-hemolytic streptococcus; GOT: Glutamic oxaloacetic transaminase; GPT: Glutamic-pyruvic; GTT: Gamma-glutamyl transpeptidase; Hb: Hemoglobin; NSTI: Necrotizing soft tissue infections; STSS: Streptococcal toxic shock syndrome}

\section{Acknowledgements}

We thank parents of the patient for their interest and cooperation.

\section{Funding}

This study was supported by Zhejiang Provincial Department of Education (grant No: 20140127) and Department of Science and Technology of Guangdong Province (grant No: 2015B09092002). The funding bodies have no role in the design of the study, collection, analysis, and interpretation of data and in writing the manuscript.

\section{Availability of data and materials}

The clinical data used during the current study are available from the corresponding author on reasonable request. If clinical data are shared, they will be anonymised.

\section{Authors' contributions}

$J L P$ and JS are responsible for general conception and design, coordinated and finalized the manuscript. JT and XJ are responsible for data collection and analysis. $X J$ drafted the first version of the manuscript. All authors read and approved the final draft of the manuscript.

\section{Ethics approval and consent to participate}

This study was approved by the Ethical committee for clinical research of Zhejiang University School of Medicine, Hangzhou, China. Written informed consent to participate in this case study was obtained form the patients' parents according to the provisions of the Declaration of Helsinki.

\section{Consent for publication}

Written informed consent for publication this case report and accompanying images were obtained from the patients' parents. Copies of the signed informed consent form are available for review by the Series Editor of BMC Pediatrics.

Competing interests

The authors declare that they have no competing interests.

\section{Publisher's Note}

Springer Nature remains neutral with regard to jurisdictional claims in published maps and institutional affiliations.

\section{Author details}

${ }^{1}$ Department of Stomatology, Hangzhou Hospital of Traditional Chinese Medicine, Hangzhou 310007, Zhejiang, China. ${ }^{2}$ Key Laboratory of Oral Medicine, Guangzhou Institute of Oral Disease, Stomatological Hospital of Guangzhou Medical University, Guangzhou 510140, China. ${ }^{3}$ Department of Stomatology, Children's Hospital, Zhejiang University School of Medicine, NO.3333 Binsheng Road, Hangzhou 310052, Zhejiang Province, People's Republic of China.

Received: 17 May 2017 Accepted: 13 June 2018

Published online: 22 June 2018

\section{References}

1. Bruun T, Kittang BR, de Hoog BJ, Aardal S, Flaatten HK, Langeland N, et al. Necrotizing soft tissue infections caused by Streptococcus pyogenes and Streptococcus dysgalactiae subsp. Equisimilis of groups $C$ and $\mathrm{G}$ in western Norway. Clin Microbiol Infect. 2013;19:545-50.

2. Mikic D, Bojic I, Djokic M, Stanuc V, Micevic D, Rudnjanin S, et al. Necrotizing fascilitis caused by group a streptococcus. Vojnosanit Pregl. 2002;59:203-7.

3. Carapetis JR, Steer AC, Mulholand EK, Weber M. The global burden of group a streptococcal disease. Lancet Infect Dis. 2005;5:685-94.

4. Hynes W. Virulence factors of the group a streptococci and genes that regulate their expression. Front Biosci. 2004;9:3399-433.

5. Steer AC, Lamagni T, Curtis N, Carapetis JR. Invasive group a streptococcal disease: epidemiology, pathogenesis and management. Drugs. 2012;72:1213-27.

6. Dhanda V, Vohra H, Kumar R. Virulence potential of group a streptococci isolated from throat cultures of children from North India. Indian J Med Res. 2011:133:674-80.

7. Bidet P, Bonacorsi S. Streptococcus pyogenes pathogenic factors. Arch Pediatr. 2014;21:54-61.

8. Naseer U, Steinbakk M, Blystad H, Cauqant DA. Epidemiology of invasive group a streptococcal infections in Norway 2010-2014: a retrospective cohort study. Eur J Clin Microbiol Infect Dis. 2016;35:1639-48.

9. O'Louqhlin RE, Roberson A, Cieslak PR, Lynfield R, Gershman K, Craiq A, et al. The epidemiology of invasive group a streptococcal infection and potential vaccine implications: United States, 2000-2004. Clin Infect Dis. 2007:45:853-62.

10. Ki V, Rotstein C. Bacterial skin and soft tissue infections in adults: a review of their epidemiology, pathogenesis, diagnosis, treatment and site of care. Can J Infect Dis Med Microbiol. 2008;19:173-84. 
11. Gabillot-Carre M, Roujeau JC. Acute bacterial skin infections and cellulitis. Curr Opin Infect Dis. 2007;20:118-23.

12. Kowalski TJ, Berbari EF, Osmon DR. Epidemiology, treatment, and prevention of community-acquired methicillin-resistant Staphylococcus aureus infections. Mayo Clin Proc. 2005;80:1201-7.

13. Lamagni TL, Neal S, Keshishian C, Powell D, Potz N, Pebody R, et al. Predicators of death after severe Streptococcus pyogenes infection. Emerg Infect Dis. 2009;15:1304-7.

14. Mikic D, Bojic I, Djokic M. Streptococcal toxic shock syndrome. Vojnosanit Pregl. 2000;57:585-9.

15. Stevens DL, Bisno AL, Chambers HF, Dellinger EP, Goldstein EJ, Gorbach SL, et al. Practice guidelines for the diagnosis and management of skin and soft tissue infections: 2014 update by the infectious disease Society of America. Clin Infect Dis. 2014;59:10-52.

16. Baron EJ, Miller JM, Weinstein MP, Richter SS, Gilligan PH, Thomson RB, et al. A guide to utilization of the microbiology laboratory for diagnosis of infectious diseases: 2013 recommendations by the infectious disease Society of America (IDSA) and the American Society for Microbiology (ASM). Clin Infect Dis. 2013;57:22-121.

17. Marin JR, Dean AJ, Bilker WB, Panebianco NL, Brown NJ, Alpern ER. Emergency ultrasound- assisted examination of skin and soft tissue infections in the pediatric emergency department. Acad Emerg Med. 2013;20:545-53.

18. Meleney FL. Hemolytic streptococcus gangrene. Arch Surg. 1924;9:317-64.

19. Riefler JF. Necrotizing fasciitis of the lip due to group a streptococcus. Inf Med. 1990;7:16-23

20. Cone LA, Woodard DR, Schlievert PM, Tomory GS. Clinical and bacteriologic observations of a toxic shock-like syndrome due to Streptococcus pyogenes. N Engl J Med. 1987;317:146-9.

21. Ramakrishnan K, Salinas RC, Agudelo Higuita NI. Skin and soft tissue infections. Am Fam Physician. 2015;92:474-83.

22. Sharma S, Verma KK. Skin and soft tissue infection. Indian J Pediatr. 2001:68:46-50.

23. Kaplan EL, Chhatwal GS, Rohde M. Reduced ability of penicillin to eradicate ingested group a streptococci from epithelial cells: clinical and pathogenetic implications. Clin Infect Dis. 2006:43:1398-406.

24. Miles LT, Jacobs JB, Gittelman PD, Lebowitz AS. Streptococcal gangrene of the head and neck: a case report and review of the literature. Head Neck. 1992:2:143-7.

\section{Ready to submit your research? Choose BMC and benefit from:}

- fast, convenient online submission

- thorough peer review by experienced researchers in your field

- rapid publication on acceptance

- support for research data, including large and complex data types

- gold Open Access which fosters wider collaboration and increased citations

- maximum visibility for your research: over $100 \mathrm{M}$ website views per year

At BMC, research is always in progress.

Learn more biomedcentral.com/submissions 